\title{
A Abordagem Ciência-Tecnologia-Sociedade no Ensino de Química
}

\author{
The Sscience-Technology-Society Approach in Teaching Chemistry
}

\author{
Rose Mary Latini ${ }^{1}$ | rose.latini@gmail.com \\ Maria Bernadete P. dos Santos ${ }^{1}$ | mbpsantos@gmail.com \\ Fátima de Paiva Canesin ${ }^{1}$ | fatimacanesin@yahoo.com.br \\ Patrícia F.S.M.Cotelo² | pat.cotelo@gmail.com
}

\section{RESUMO}

O objetivo deste trabalho é relatar a inserção da abordagem do conteúdo de polímeros, no ensino-aprendizagem de Química, em uma turma de Ensino Médio de uma escola pública no estado do Rio de Janeiro e analisar tal abordagem com base nas categorias de ensino em CTS proposta por Aikenhead (1994). A observação participante foi o método de coleta de dados escolhido por ser a sala de aula o cenário de investigação. Os resultados apontam que embora a abordagem CTS tenha sido utilizada para organizar o conteúdo de Química e a sua sequência o conteúdo CTS foi o foco da abordagem. E, embora a introdução deste tema possa favorecer o entendimento da relação entre ciência-tecnologia-sociedade, consideramos que para uma prática mais dialógica e comprometida com a realidade científica, tecnológica e socioambiental são necessários novos posicionamentos de alunos e professores.

Palavras-chave: Ensino de química, ciência-tecnologia e sociedade, polímeros.

\section{ABSTRACT}

This study has as objective to report the insertion of the polymer's content approach in the teaching-learning in Chemistry, on a public high school class, in the Rio de Janeiro state, in Brazil, and investigate that approach on the basis of learning categories' in Science, Technology and Society (CTS) proposed by Aikenhead(1994). The method of data acquisition selected was participant observation due to the classroom be the investigation scenery. Although CTS approach had been used to organize Chemistry content and its sequence, the results has been pointed that CTS content was the approach focus. Although the introduction of this subject might benefit the understanding of the relationship between science-technology-society, we consider that for a more dialogical and compromised practice with the scientific, technologic and socio environmental reality are required new students and teacher's positions.

Key-words: Chemistry teaching, science, technology and society, polymers.

1 Programa de Pós-Graduação em Ensino de Ciências da Natureza/UFF e Departamento de Físico-Química/UFF

2 - Professora da SEEDUC/RJ. 


\section{INTRODUÇÃO}

Dentre os objetivos principais dos Parâmetros Curriculares Nacionais para o ensino de Química existem dois que merecem ser destacados como o que estabelece a "ligação do conhecimento científico com o que está a sua volta, assim como as causas e as consequências dos fenômenos químicos nas mais diversas áreas e no mundo real” e aquele que diz que "o conhecimento químico não deve ser entendido como um conjunto de conhecimentos isolados, prontos e acabados” (BRASIL, 2006). Portanto, tais objetivos ratificam a relevância da inserção de questões atuais no ensino de Química, pois além de possibilitar o estabelecimento de relações deste campo de saber com realidade dos alunos, possibilita uma melhor assimilação do conhecimento construído em sala de aula.

No tocante a temas atuais, a problemática da utilização de plásticos no dia a dia permite a abordagem de polímeros, um dos conteúdos exigidos nos programas de ensino de Química, que pode ser empregado na (re) construção do conhecimento químico, explorando as propriedades físico-químicas, reações de polimerização, estruturas poliméricas e identificação de funções orgânicas. Além disso, os problemas sociais causados pelas embalagens plásticas devido aos avanços tecnológicos tais como: consumo acelerado de itens constituídos de materiais plásticos, quantidade crescente dos resíduos sólidos, ineficácia do seu gerenciamento e os danos causados ao meio ambiente e à saúde da população; servem de estratégia metodológica para a abordagem destes conteúdos permitindo o estabelecimento de relações entre ciência, tecnologia e sociedade (CTS) e contribui para o desenvolvimento de uma consciência ambiental.

O tema "lixo" e todas as implicações que a sua produção causa à sociedade é uma das principais discussões afetas a temática ambiental no ambiente escolar (TRAJBER e MENDONÇA, 2006). Entretanto, para seguir as recomendações contidas nos PCN e as perspectivas atuais em Ensino de Ciências (SANTOS e MORTIMER, 2002) é preciso uma prática pedagógica mais dialógica e comprometida com a problemática socioambiental, diretamente relacionada com a ciência e a tecnologia, tratando das questões globais críticas, suas causas e inter-relações em uma perspectiva sistêmica, em seu contexto social e histórico. (LAYRARGUES, 2004 e CARVALHO, 2004).

Considerando tal estratégia de ensino o tema permite uma visão mais ampla e crítica destes conteúdos, tendo em vista que podem ser introduzidas discussões sobre as etapas dos processos produtivos, dos aspectos ambientais e sociais ligados a estes processos, da relação entre produção e consumo, dos usos, da disposição, do reuso e da reciclagem. Santos (2006) aponta que para preparar cidadãos que sejam capazes de participar das decisões, acerca dos processos de produção do conhecimento científico-tecnológico e de suas implicações na sociedade e na qualidade de vida de cada cidadão, é preciso “... fornecer uma aprendizagem comprometida com as dimensões sociais, políticas e econômica que permeiam as relações com ciência, tecnologia e sociedade”.

Nesta perspectiva, concordamos com Santos (2006), que o Ensino de Ciência necessita caminhar no sentido de possibilitar a inserção e a participação do cidadão na vida social, a partir de uma formação científica e tecnológica que torne possível a compreensão e as possíveis soluções de problemas da sociedade. Para Santos e Mortimer (2002, p.3), as propostas em CTS no ensino médio devem ir além e contribuir também para a construção de habilidades e de valores relacionados aos interesses coletivos. E, a escola como lócus de formação e irradiação de conhecimento deve contribuir para tal, através de um ensino que permita não somente a leitura de mundo, mas também entender como transformar este mundo em algo melhor para todos (CHASSOT, 2003).

Considerando-se todos esses aspectos nos questionamos de que forma poderia ser introduzido na sala de aula de Química, o conteúdo de polímeros a partir do tema resíduos sólidos de forma que este estabelecesse relações com CTS. De acordo com Santos e Mortimer (2002, p.12), pesquisas sobre estratégias de ensino mais efetivas em CTS apontam que estas devem iniciar com "um problema social, seguida da análise da tecnologia relacionada, dos estudos do conteúdo científico e de tecnologias correlatas em função do conteúdo abordado e por fim da discussão da questão social original”. Assim, pensamos que tal estratégia de ensino não deveria partir do conteúdo formal de química, mas sim de uma problemática socioambiental, na qual se situam a ciência e a 
tecnologia, para somente depois desenvolver os conteúdos relevantes de química para compreensão da problemática envolvida.

Pretendeu-se, dessa forma, inserir no processo de ensino-aprendizagem uma visão mais abrangente de polímeros com uma reflexão crítica sobre os benefícios e os impactos dos plásticos no ambiente. Apresentamos nossos questionamentos a uma professora de química da rede estadual do Rio de Janeiro, que aceitou introduzir esta estratégia de ensino nas turmas em que lecionava. Antes de iniciar a inserção da proposta ela participou de discussões sobre a perspectiva CTS em sala de aula a partir da leitura de artigos oriundos de periódicos da área de Ensino de Ciências. Ela destacou características da escola e das turmas onde poderia desenvolver a proposta e, chamou atenção para o calendário escolar, que previa atividades diversas a serem desenvolvidas, tais como, datas de provas de avaliação e recuperação, atividades avaliativas complementares, além dos conteúdos programáticos.

Organizamos com a professora um levantamento inicial sobre o entendimento dos alunos a respeito de resíduos sólidos e, combinamos que, a partir daí ela organizaria a sequência didática, assim como definiria os recursos didáticos, a serem utilizados considerando também o planejamento das atividades na escola.

Assim, o objetivo deste trabalho é relatar a inserção desta proposta de abordagem do conteúdo de polímeros, no ensino de Química, em uma turma de Ensino Médio de uma escola pública no estado do Rio de Janeiro e analisar tal abordagem com base nas categorias de ensino em CTS proposta por Aikenhead (1994). Tal reflexão justifica-se tendo em vista que, hoje, um importante desafio para o Ensino de Ciências é a introdução de uma educação sociocientífica e tecnológica no ensino, que passa desde a preparação de professores até a redefinição de conteúdos programáticos (ACEVEDO-DÍAZ et al, 2005).

\section{ENCAMINHAMENTOS METODOLÓGICOS}

Este é um estudo qualitativo de cunho descritivo e interpretativo pela possibilidade de se focar em um objeto específico (BODGAN e BIKLEN, 1994). A observação participante foi o método de coleta de dados escolhido por ser a sala de aula o cenário de investigação. Para Haguete (1987) a observação participante é um processo no qual

a presença do observador numa situação social é mantida para fins de investigação científica. O observador está em relação face a face com os observados, e, em participando com eles em seu ambiente natural de vida, coletar dados. Logo, o observador é parte do contexto, sendo observado, no qual ele ao mesmo tempo modifica e é modificado por este contexto.

O cenário escolhido foi uma escola da rede pública de ensino regular, localizado em um bairro de Niterói, de classe média a média-baixa, no Estado do Rio de Janeiro. Recebe alunos, em sua maioria, moradores do entorno escolar. Participaram da pesquisa 55 alunos das duas turmas da 3a série da referida escola do turno da manhã.

A escola dispõe de um Laboratório de Ciências com recursos para desenvolvimento de algumas atividades experimentais, bem como recursos audiovisuais. Na rede estadual do Rio de Janeiro o tempo de aula de Química no ensino médio é de duas horas/aula semanais. Para o desenvolvimento das atividades aqui relatadas foram utilizadas dez horas/aulas do quarto bimestre, no qual é previsto o conteúdo de polímeros.

A partir de 2011, as escolas estaduais vinculadas a Secretaria de Estado de Educação do Rio de Janeiro passaram a seguir as orientações do Currículo Mínimo. Este documento apresenta todas as competências e habilidades que devem estar nos planos de curso e aulas das diferentes disciplinas, listadas por série e bimestres. Para a disciplina Química o Currículo Mínimo estabelece para o quarto bimestre os conteúdos de Biomoléculas e Polímeros e as seguintes habilidades e competências: 
Problematizar o uso dos plásticos em nosso dia a dia, utilizando campos temáticos tais como poluição, reciclagem, armazenamento, incineração.

Reconhecer a importância da Química para a inovação científica e tecnológica nas sociedades modernas, enfatizando suas contribuições nos campos da Biotecnologia, Saúde Humana, Nanotecnologia, desenvolvimento de novos materiais e novas matrizes energéticas (SEERJ, 2012, p.10)

A análise dos dados levou em consideração que a palavra é "material primordial da investigação qualitativa, que expressa a fala cotidiana, seja nas relações afetivas e técnicas, seja nos discursos intelectuais, burocráticos e políticos” (MINAYO E SANCHES, 1993 p.245). Neste sentido, a palavra

..... torna-se reveladora de condições estruturais, de sistemas de valores, normas e símbolos (sendo ela mesma um deles), e, ao mesmo tempo, possui a magia de transmitir, através de um porta-voz (o sujeito), representações de grupos determinados em condições históricas, sócio-econômicas e culturais específicas. (op cit p.245).

Neste relato utilizamos a fala na sala de aula, oral e escrita, de todos os sujeitos envolvidos, professor e alunos, para compreender de que forma o conteúdo de polímeros, que teve a intencionalidade de incluir a perspectiva CTS, foi introduzido. Tal análise teve por base as categorias de ensino em CTS proposta por Aikenhead (1994), cuja categorização foi estabelecida com base "na prioridade que é atribuída aos objetivos CTS e a proporção entre o conteúdo de CTS e o conteúdo puro de ciências” (SANTOS e MORTIMER, 2002).

Embora Aikenhead utilize categorias de ensino em CTS para classificar cursos que apresentem propostas assim denominadas, onde os temas estruturam o currículo, nos apropriamos desta categorização para analisar esta abordagem no conteúdo de polímeros dentro da disciplina de química, já que, de fato, na maioria das escolas brasileiras não são os temas que estruturam o currículo, mas ainda são os conteúdos que abarcam temas em CTS.

De acordo com o autor são oito as categorias de ensino em CTS (1) Conteúdo de CTS como elemento de motivação. (2) Incorporação eventual do conteúdo de CTS ao conteúdo programático. (3) Incorporação sistemática do conteúdo de CTS ao conteúdo programático. (4) Disciplina científica (Química, Física e Biologia) por meio de conteúdo de CTS. (5) Ciências por meio o conteúdo de CTS. (6) Ciências com conteúdo de CTS. (7) Incorporação das Ciências ao conteúdo de CTS. (8) Conteúdo de CTS. Desta forma, entendemos que tais categorias podem ser utilizadas para analisar a inserção desta abordagem nas disciplinas de ciências.

\section{RELATANDO A EXPERIÊNCIA}

A introdução desta proposta, em sala de aula, foi iniciada com uma diagnose, que teve por propósito identificar os conhecimentos prévios dos alunos sobre resíduos sólidos e impactos ambientais etc. A diagnose foi realizada, em sala de aula, por meio da aplicação de um questionário com perguntas abertas.

As perguntas foram: o que é lixo para você? Quais os produtos que você acha que estão mais presentes no lixo? Alguns desses produtos têm valor econômico? Quais? Por quê? O lixo causa algum tipo de problema? Quais? O que pode ser feito para solucionar os problemas citados na questão anterior?

Inicialmente, foi realizada a leitura do conteúdo das respostas dos alunos por turma, mas como não houve diferença entre os tipos de respostas dadas nas turmas, as falas abaixo relatadas, referem-se ao resultado da análise textual (MORAES, 2003) englobando as duas turmas. Esta análise foi feita juntamente com a professora da turma.

Apenas três alunos relataram que o "lixo é tudo que não presta pra mim" e que "pode ser jogado fora porque não tem mais nenhum valor”. Para a maioria dos alunos, o lixo é algo que não serve mais para ser aproveitado após reciclagem e/ou reutilização. 
Lixo é tudo aquilo que não pode ser reaproveitado

Tudo aquilo que não pode ser reciclado.

Reconhecem que os produtos mais presentes no lixo são o plástico, vidro, papelão, entulho e restos de alimento e os que possuem valor econômico são os mais citados como presentes no lixo: o plástico, o papelão e o vidro.

As garrafas, plásticos e papelão são classificados na área da reciclagem e podem gerar produtos para revender.

Os materiais recicláveis. Pois, por serem recicláveis podem ser reaproveitados e podem voltar a serem materiais para uso, sem desperdícios e com diminuição de agressão ao meio ambiente.

Eles compreendem o valor econômico do lixo a partir da reciclagem e/ou reaproveitamento, mas poucos percebem a relação entre a geração de lixo e o consumo de bens naturais. Apenas um aluno estabeleceu relação entre produtos e utilização de recursos naturais.

Garrafas plásticas, plástico, papel e outros produtos que são renováveis. Porque em vez de derrubar árvores, podemos reciclar preservando o meio ambiente e a natureza. Já com a garrafa plástica pode fazer sofá, cadeira, calha e gerar produtos com valor econômico.

Para a maioria deles a reciclagem e/ou reaproveitamento está relacionado com uma geração de lucro imediata, isto é, eles não estabelecem relação entre o produto encontrado no lixo (disposição final) e a sua origem (matéria-prima).

Com relação às perguntas O lixo causa algum tipo de problema? Quais? A totalidade dos alunos relaciona o lixo com problemas ambientais, sociais e/ou de saúde e, alguns ainda estabelecem esta relação quando do descarte incorreto.

Sim. Pilhas e baterias demoram a se decompor e têm produtos químicos que afetam tanto o meio ambiente quanto o ser humano, sacolas jogadas no meio ambiente afetam o ecossistema.

Sim. Podem poluir rios, lagos e oceanos, provocam deslizamentos e ainda tem o problema do mau cheiro.

Podem causar doenças e enchentes.

Quanto ao que pode ser feito para solucionar os problemas citados na questão anterior, os alunos responderam que: a informação da população, o descarte e tratamento adequados do lixo, a coleta seletiva, o saneamento básico e, principalmente a reciclagem, poderiam solucionar este problema.

Jogar lixo no lugar certo, parar de jogar lixos nas ruas e evitar usar produtos que demoram a se decompor.

Devem-se descartar os lixos com consciência e com obrigação da prefeitura e do governo, ter estrutura e condições para tratar o lixo para que não afete o meio ambiente.

Trabalhar com a reciclagem. E é legal separarmos papel, lixo, orgânico, e vidro para que quando for para o lixão ser mais fácil separar. 
Observamos na fala dos alunos que estes reconhecem o plástico como o material mais presente no lixo e que o valor econômico e a solução para os problemas causados pelo lixo estão na reciclagem. Além de a reciclagem ser um tema bastante difundido pela mídia como uma solução para o lixo é também, depois do tema água, o mais discutido nas escolas brasileiras no tocante à temática ambiental (TRAJBER e MENDONÇA, 2006).

A fala dos alunos corrobora com a pesquisa realizada por Latini e Souza (2011) que demonstra que o tema lixo é o que mais aparece relacionado com o ensino de química em publicações na revista Química Nova da Escola. As autoras destacam, entretanto, que os artigos priorizam o impacto do lixo no ambiente, o seu tratamento e a reciclagem, mas, não levam em consideração que "nosso sistema produtivo está apoiado na exploração e transformação de recursos naturais" deslocando estas discussões na escola do "modo de produção que a define e situa” (LOUREIRO, 2005, p.1475).

Neste cenário, a reciclagem surge como um mito, capaz de solucionar os problemas ambientais, econômicos e sociais. Assim,

\begin{abstract}
a abordagem hierárquica dos 3R's parece ser a mais lógica e promissora estratégia de gerenciamento de resíduos, como afirmam Eigenheer e Layrargues, que acentuam o fato do reduzir na origem ser a alternativa preferível, pois se o resíduo não é gerado, não é gerado também um problema de controle de resíduo. No entanto, esta opção conflitua com o sistema capitalista vigente de consumir indefinidamente. A reciclagem surge então, como "solucionador” dos problemas causados por este crescente consumo, constituindo-se um mito (MIRANDA et al, 2005).
\end{abstract}

Tal visão de reciclagem vai ao encontro de uma perspectiva linear da relação CTS (LÓPEZ et al, 2003) onde a ciência e tecnologia são capazes de produzir bem estar social e ambiental, dissociando desta os impactos causados pelo consumo desenfreado em detrimento dos recursos naturais.

A seguir foi discutido com as turmas o conteúdo da diagnose, sendo a reciclagem de latas de alumínio o tema predominante na discussão, provavelmente por ser o tipo de reciclagem mais presente no dia a dia. Neste momento a professora comentou a respeito da extração e beneficiamento de bauxita para produção de alumínio e da economia de recursos naturais quando se faz a reciclagem. Foram também apresentadas questões sobre diferentes formas de disposição final do lixo e suas implicações ambientais.

Para ampliar a discussão sobre ciência, tecnologia e sociedade foram exibidos três vídeos, todos selecionados pela professora. O primeiro sobre plásticos onde se destacam a produção dos polímeros, a tecnologia envolvida para a produção dos diferentes tipos de plásticos e dos processos de reaproveitamento da matéria-prima e os impactos socioambientais decorrentes do seu uso. O vídeo exibido foi "De onde vem o plástico" da TV Escola, que apresenta em linguagem coloquial a origem, a produção, aplicações e reciclagem do plástico. Aprofundando o tema, o segundo o vídeo foi “Polímeros Sintéticos” da Sociedade Brasileira de Química, que destaca além dos aspectos apresentados no vídeo anterior, o conteúdo de química referente aos polímeros, os impactos ambientais decorrentes da disposição inadequada e projetos sociais baseados em reuso de plásticos. O filme mostra também, uma experiência no subúrbio do Rio de Janeiro sobre a construção de puffs e poltronas de garrafa PET. Após a exibição do filme foi ainda discutido com os alunos outros usos para o PET, que eles já conheciam como confecção de camisas, de casas, de muros, de bolsas e etc.

Dando continuidade, a professora apresentou os conteúdos de química referentes aos polímeros, trabalhando com as reações de produção por adição e por condensação. Apresentando também os diferentes polímeros e seus usos.

O terceiro e último vídeo, “A História das Coisas”, traz para discussão questões políticas e sociais e o consumo desenfreado de recursos naturais. O vídeo, que retrata como a política do consumo é utilizada para manutenção do sistema capitalista, com desrespeito às sociedades, à cultura e ao meio ambiente. 
A seguir foi solicitado aos alunos que trouxessem embalagens plásticas para a próxima aula. Com os plásticos trazidos pelos alunos e outros levados pela própria professora foram abordados os símbolos de reciclagem para os diferentes tipos de plásticos e o código de cores dos recipientes de descarte dos diferentes tipos de resíduos.

Ampliando a discussão foram exibidos um vídeo sobre Lixo Eletrônico do Globo Ecologia e uma reportagem no programa "Cidades e Soluções”, do Globo News, falando sobre logística reversa e Política Nacional de Resíduos Sólidos. Alguns alunos relataram conhecer característica da logística reversa baseados nas suas experiências com a segregação de pilhas.

De acordo com a professora, após a exibição dos vídeos era sempre aberto um espaço para a discussão. Entretanto, a participação dos alunos em relação ao tema era sempre muito pequena, reduzindo-se a poucas palavras. Relata que o mesmo aconteceu com as outras atividades propostas. Tal comportamento nos remete a Freire (2005, p.66) quanto fala das características de uma educação bancária. Estes alunos, provavelmente, acostumados ao tradicionalismo de aulas onde o professor narra conteúdos e eles memorizam mecanicamente estes conteúdos apresentam dificuldades para se expressarem. Parecem aceitar "docilmente” serem "vasilhas, recipientes, a serem enchidos pelo educador”

Dando continuidade foi realizada uma atividade experimental, lúdica, denominada “Amoeba”, também conhecida por crianças e adolescentes como "Geleca” onde o objetivo foi produzir um tipo de polímero e discutir as suas propriedades.

Por fim, visando cumprir a forma de avaliação prevista pela escola a professora elaborou uma prova com questões objetivas referentes aos conteúdos de química (polímeros) e; tendo em vista a pouca participação oral dos alunos em sala de aula incluiu, também, questões objetivas para verificação do conhecimento a respeito dos resíduos sólidos. Assim, a avaliação da aprendizagem utilizada foi a tradicional prova para verificação de conteúdos aprendidos, a qual permitiu identificar que muitos dos alunos ampliaram os seus conhecimentos sobre resíduos sólidos, tais como: Política Nacional, manejo correto, implicações relacionadas com o ambiente e com a saúde, logística reversa dentre outros.

A professora ressaltou ainda que o tempo utilizado para esta abordagem foi possível, pois neste período estava previsto apenas o conteúdo de polímeros e biomoléculas, conteúdo este que na Escola prevê conhecimentos básicos relativos ao tema, conforme consta do Currículo Mínimo do Rio de Janeiro, já citado anteriormente. Para tempos menores seria necessária uma adequação das atividades realizadas.

\section{CONSIDERAÇÕES FINAIS}

O tema resíduos sólidos (lixo) foi utilizado como um tema social em CTS e estruturador do conteúdo de polímeros, conteúdo previsto para o período em que esta metodologia foi aplicada. A sequência utilizada: a identificação dos conhecimentos prévios dos alunos; a introdução dos aspectos científicos e tecnológicos relativos ao tema; as implicações políticas e socioambientais e a retomada dos aspectos científicos sugere a classificação desta abordagem na categoria 4, proposta por Aikenhead,1994:

Os temas de CTS são utilizados para organizar o conteúdo de ciências e a sua seqüência, mas a seleção do conteúdo científico ainda é a feita partir de uma disciplina (p.15 e 16).

Entretanto, embora para o autor esta categoria tenha uma maior ênfase no ensino conceitual de ciências, percebemos na proposta relatada que os conceitos de polímeros aparecem em três das dez aulas destinadas para esse fim: vídeo da Sociedade Brasileira de Química, uma aula expositiva de química e uma atividade experimental no laboratório. Destacamos que nestas aulas as reações de polimerização e os tipos polímeros são apenas apresentados não se dando ênfase ao aprofundamento do conteúdo. Assim, no relato apresentado observamos 
que o conteúdo de CTS é também determinante no desenvolvimento do conteúdo de ciências (polímeros). Nessa perspectiva, a prática se aproxima também da descrição da categoria 7 , que relata que:

O conteúdo de CTS é o foco do currículo. O conteúdo relevante de ciências é mencionado, mas não é ensinado sistematicamente. Pode ser dada ênfase aos princípios gerais da ciência (op. cit., p.16).

Observamos também no relato que embora os recursos utilizados pelo professor favoreçam uma ampliação das relações entre CTS foi pequena a participação dos alunos, talvez pelo pouco tempo para discussões acerca das questões levantadas ou, pelos alunos estarem acostumados a não se posicionarem em uma aula de ciências, já que tais conteúdos são, muitas vezes, desvinculados do cotidiano deles. Assim, embora a introdução deste tema possa favorecer o entendimento da relação entre ciência-tecnologia-sociedade, entendemos que para uma prática mais dialógica e comprometida com a realidade científica, tecnológica e socioambiental são necessários novos posicionamentos de alunos e professores.

\section{REFERÊNCIAS BIBLIOGRÁFICAS}

ACEVEDO DÍAZ, J. A.; VÁZQUEZ ALONSO, A.; MANASSERO MAS, M. A. y ACEVEDO ROMERO, P. Aplicación de una nueva metodología para evaluar las creencias del profesorado sobre la tecnología y sus relaciones con la ciência. Educação Química, 16(3). jiulho, 2005, pp 372-382.

AIKENHEAD, G. S. What is STS science teaching? In: Solomon, J., Aikenhead, G. STS Education: International perspectives on reform. New York: Teachers College Press, 1994, p.47-59.

BOGDAN, R.; BIKLEN, S. Investigação qualitativa em educação. Porto: Porto Editora, 1994

CARVALHO, I. C. M. Educação ambiental: a formação do sujeito ecológico. São Paulo: Cortez, 2004.

CHASSOT, A. Alfabetização Científica: uma possibilidade para a inclusão social. Revista Brasileira de Educação, Anped Jan/Fev/Mar/Abr n. 22, 2003.

FREIRE, P. Pedagogia do Oprimido. 47. ed. Rio de Janeiro: Paz e Terra, 2005.

HAGUETE, T.M.F. Metodologias qualitativas na sociologia. Petrópolis, Vozes, 1987.

BRASIL, Parâmetros Curriculares Nacionais: Ciência da Natureza, Matemática e suas Tecnologias (PCN+), 2006.

LATINI, R.M. e SOUSA, A.C. Ensino de Química e Ambiente: as articulações presentes na revista Química nova na Escola (QNEsc), Investigações em Ensino de Ciências - V16(1), 2011pp. 143-159,

LAYRARGUES, P.P.(Coord.). Identidades da Educação Ambiental Brasileira. Ministério do Meio Ambiente. Diretoria de Educação Ambiental. Brasília, 2004 Acesso em mar.,2013 http://www.aja.org.br/publications/livro_ ieab.pdf

LÓPEZ, C.; LUJÁN, J.L.; MARTÍN, G. M.e OSORIO, C. Introdução aos estudos CTS (Ciência, Tecnologia e Sociedade). Madrid: OEI, 2003.

LOUREIRO, C.F.B. Complexidade e dialética: contribuições à práxis política e emancipatória em educação ambiental. Educação e Sociedade. 2005, vol.26, n.93, pp. 1473-1494.

MINAYO, M.C. e SANCHES, O. Quantitativo-Qualitativo: Oposição ou Complementaridade. Cadernos de Saúde Pública. RJ, 9, (jul/set, 19933): 239-262

MIRANDA, A. C.; SILVA, E. M.; MONTEIRO, R. C. A Dimensão do Mito: na Cosmologia; na Educação Ambiental; na História em Quadrinhos. São Paulo: All Print, 2005. 
MORAES. R. Uma tempestade de luz: a compreensão possibilitada pela análise textual discursiva. Ciências e Educação, v. 9, n. 2, 2003, p. 191-211.

SANTOS, P. R. dos. O Ensino de Ciências e a idéia de cidadania. Mirandum. Ano X, 2006, n. 17.

SANTOS, W.L.P e MORTIMER, E.F. Uma análise de pressupostos teóricos da abordagem C-T-S (Ciência Tecnologia- Sociedade) no contexto da educação brasileira.Ensaio - Pesquisa em Educação em Ciências, 2002,V.2, N. p.1-23

SEERJ. Secretaria de Estado e Educação. Currículo Mínimo de Química. Governo do Estado do Rio de Janeiro, 2012 TRAJBER, R e MENDONÇA, P. R. (2006). Educação na diversidade: o que fazem as escolas que dizem que fazem educação ambiental - Brasília: Secretaria de Educação Continuada, Alfabetização e Diversidade. Coleção Educação para Todos, Série Avaliação; n. 6, v. 23, 256 p 